\title{
Comparison of different ORC typologies for heavy-duty trucks by means of a thermo- economic optimization
}

\author{
Ludovic Guillaume ${ }^{a}$, Vincent Lemort ${ }^{\mathrm{a}}$ \\ ${ }^{a}$ Thermodynamic Laboratory, University of Liege, ludovic.guillaume@uliege.be
}

\begin{abstract}
:
This study focuses on the design phase of ORC systems recovering the heat wasted from two of the sources available on a Heavy-Duty Truck (HDT): the exhaust and recirculated gases. From these heat sources and their combinations, 5 possible architectures are considered. The main components (i.e. the heat exchangers, the pump and the expander) of the WHR systems are investigated and modeled. Plate type heat exchangers are considered for both the hot and cold sides of the system. Regarding the expansion devices, 5 positive displacement machine technologies, the scroll, screw, piston, vane and roots expanders, are considered and modeled while, among the turbo-expanders, the radial-inflow turbine is taken into consideration. A semiempirical model is proposed to simulate a volumetric pump. The models of components are first confronted against experimental data. The validated models are then used as references for the design of the new components, which is achieved following similitude rules. This leads at the end to 30 typologies that will be used with 6 of the various investigated working fluids. In order to identify the most promising system(s), a 3step optimization tool is developed. First, the most suitable conditions are identified for the design of the ORC systems using a simplified model of expansion machine. In a second step, the design phase, using more detailed models for the expanders and a proposed economic model for the overall system, a thermoeconomic optimization is performed. In a third step, the output power of the obtained system models is maximized, optimizing the evaporating pressure and the superheating degree for various off-design conditions. The average power, weighted using the frequency distribution of the gas operating conditions is computed and used to compare the 180 systems. Finally, because power is not the only criterion to select the most suitable system topology, additional criteria are taken into consideration and a decision matrix is proposed.
\end{abstract}

Keywords:

Organic Rankine Cycle, Waste Heat Recovery, Heavy Duty Trucks, Thermo-Economic optimization.

\section{Introduction}

This study attempts to address the problematic of selecting the architecture, the expander technology, and the working fluid for a waste heat recovery organic (or non-organic) Rankine cycle system devoted to be coupled to a HDT engine. Many studies have already been conducted on the subject ([1], [2], [3], [4], [5], [6], [7], [8]). However, in most of the existing works, because it is generally a design process, the proposed ORC models are not validated while important differences appear between theoretical predictions and measured performance in real cases [9]. In addition, the level of detail of the models is most of the time reduced advocating a decrease in computational time [10]. It is not uncommon for instance to find constant efficiency values for most of the component models of the ORC system when it comes to working fluid and component selection, particularly in thermo-economic optimization studies, which can be greedy in computational resources [7]. If this assumption can be acceptable for the design point, it is of course not true for most of the components in off-design conditions and particularly for volumetric expansion machines. Sometimes, authors also consider the design point as the single point for the performance comparison of the various systems they investigate. Nonetheless, on-board ORC systems are operating only a fraction of the time on their design point because of the highly transient temperature and mass flow rate conditions of the heat sources and heat sinks. These are several factors that could raise some questions regarding the reliability of the results. 
In this study, it is proposed to first build and validate the component models against experimental data before trying to predict their performance within the design phase of the on-board system. A lot of experimental set-ups could be used to this end. A Rankine test bench, using water as working fluid, and devoted to recover the heat from the exhaust gases of a gasoline engine, enabled to calibrate the parameters of the Nusselt correlation on the gas side and to validate the plate heat exchanger model to be placed on the high-pressure side. Regarding the plate heat exchangers on the heat sink, because the pinch-point is generally low, it is proposed to directly use correlations available in literature to evaluate the heat transfer coefficients on both sides of the heat exchanger.

Numerous test rigs have also been built over the past few years to characterize the performance of ORC systems including various expansion machine technologies. Thus, several scroll expanders, a screw, a piston and a roots expander were tested in laboratory, using R245fa as working fluid. The rigs were also equipped with different volumetric pump technologies (single or multi diaphragm, piston, gear pumps). All this data has been used to calibrate the parameters of the proposed pump and expander models and validate those models. Finally, a collaboration with the Czech Technical University in Prague enabled to validate a model of vane expander, which was installed on test-rig using hexamethyldisiloxane (MM) as working fluid.

Numerous design steady-state models of ORCs are built. From 5 investigated architectures and 6 expander technologies result 30 different typologies. Considering 6 working fluids, it leads to the optimization of 180 ORC system models. A 3-step optimization tool is developed in the Matlab environment [11]. The method starts with the selection of the design conditions. In this first step, the model of expansion machine is simplified to only take the impact of the pressure ratio on the expander isentropic efficiency into account. The evaporating pressure and the pinch-point of the heat exchangers are optimized under several constraints, for various gas conditions coming from a combination of various truck driving cycles, so to maximize the power produced and identify the most suitable design point. Then, for the obtained design conditions, a thermo-economic optimization is performed to design the systems. In this second step, more detailed models of expansion machines are used, an economic model is proposed and additional optimization variables (e.g. expander rotational speed) and constraints (e.g. limited expander rotational speed) are taken into consideration. Finally, the performance of the resulting systems is optimized and evaluated for various off-design conditions, optimizing the evaporating pressure and the superheating degree. A weighted average of the power produced by the systems is then found based on the frequency distribution of the considered operating conditions in the driving cycle. The power produced by the system is an objective comparison criterion, but it is obviously not the only selection criterion. Many other factors have to be considered to identify the most suitable system architecture, working fluid and component for a given application. A non-exhaustive list of these factors is thus established, and a comparison methodology based on the obtained criteria is proposed.

\section{Model of the Waste Heat Recovery Systems (WHRS)}

In this section, the models of the heat exchangers, pump and expansion machines are described.

All the models are implemented in the Matlab environment. Then the models of WHR systems are built by interconnecting the models of components together, according to the investigated typologies.

\subsection{Modeling the heat exchangers}

In ORC power systems, Brazed Plate Heat Exchangers (BPHE) are often considered for the evaporator whose heat transfer performance is a key element in defining the system overall efficiency. The device is typically a once-through heat exchanger covering the phase transition from liquid to vapor. Thus, when modeling the evaporator, the liquid, two-phase and vapor regions must be taken into account. 
The proposed heat exchanger model consists in a combination of a thermodynamic and a geometric model. A summary of the model procedure is given in Figure 1. In this Figure is also shown the optimization process implemented for the calibration of the model parameters

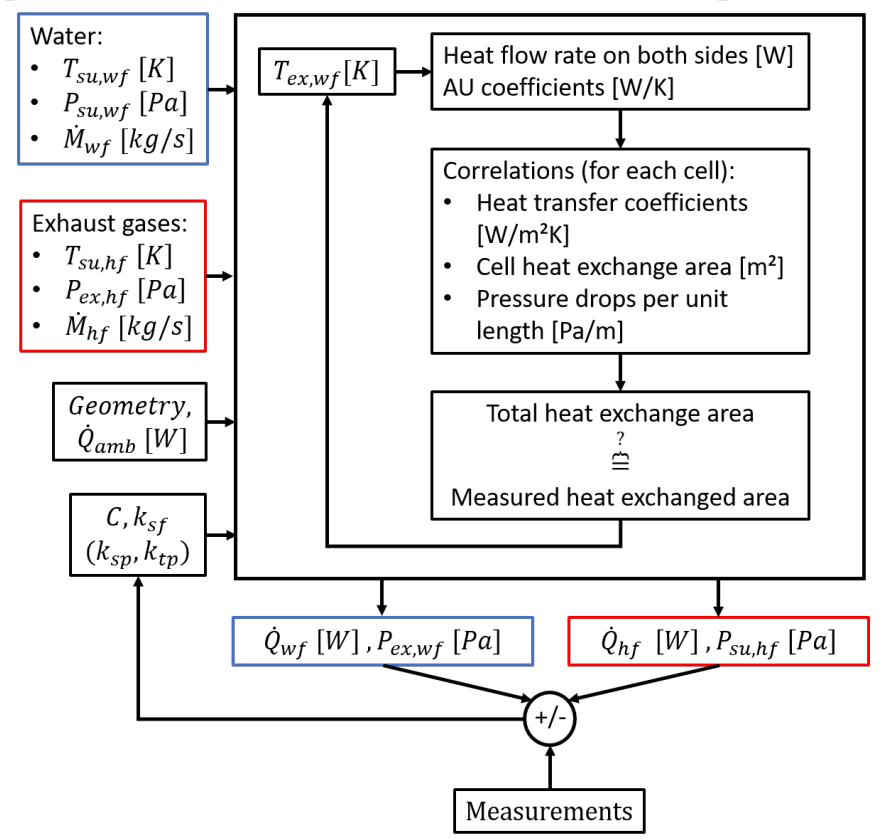

Fig. 1 Flow chart describing the inputs, outputs, modeling process and parameter calibration phase of the heat exchanger model [22]

\subsubsection{Experimental investigation}

A shell and plate heat exchanger $[12,13]$ has been experimentally investigated in laboratory. It consists in two plates welded together and bent into a spiral shape. More information about the component can be found in [14]. The device has been integrated into a Rankine system and connected to the exhaust pipe of a gasoline engine. Temperature and pressure measurements have been achieved at the inlet and outlet of the exchangers on both sides and the mass flow rates have also been recorded. At the end, around 40 steady-state measurement points have been achieved and used to calibrate and validate the model of heat exchanger proposed above. The evaporator is modeled as a counter-flow BPHE whose plate spacing depends on whether the gas side or the working fluid side is considered. An optimization process (Figure 1) is implemented to calibrate the 2 model's parameters, $C$ and $k$, minimizing the weighted MAPE between measured and predicted heat flow rates and pressure drops on the gas side. The values of the resulting parameters $C$ and $k \mathrm{f}$ are respectively 0.1 and 0.7 . The validation process consists in comparing the outputs of the model with the measured heat flow rate, exhaust temperature and pressure drop on both sides of the heat exchanger. Results are presented in Figure 3. Also Figure 2 shows a T-s diagram including the saturation curves of the working fluid and the temperature profiles of the primary and secondary fluids and of the wall during the vaporization process. As it can be seen the temperature profile of the wall is close to the temperature profile of the working fluid. This is explained by the heat transfer coefficient, which are 1 to 2 orders of magnitude higher on the water side compared to the gas side, depending on whether water is in single or two-phase state respectively. 


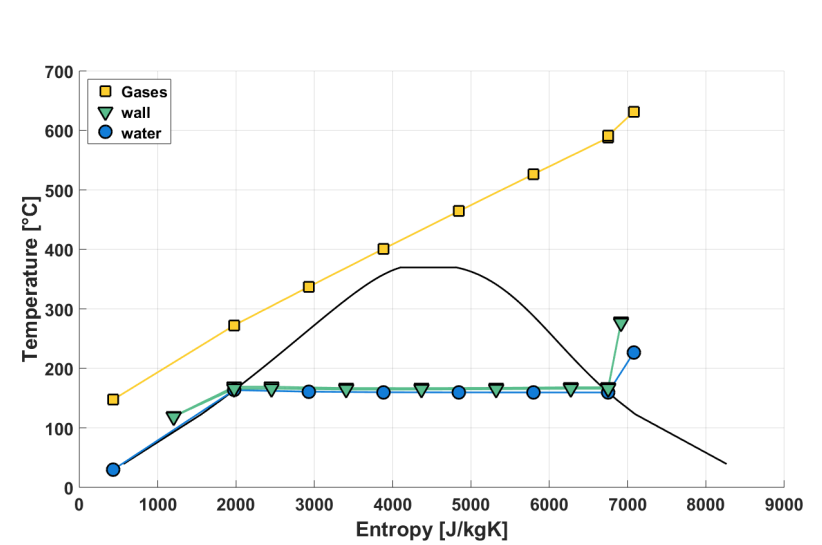

Fig. 2 T-s diagram of water and predictions of the temperature profiles of water, exhaust gases and metal wall along the counter-flow heat exchanger (X axis: entropy of the working fluid)

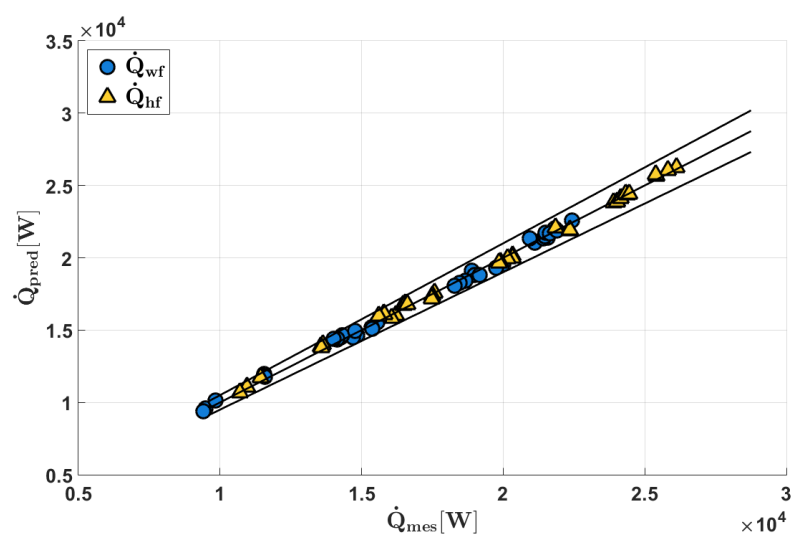

Fig.3 Comparison between measured and predicted heat flow rates on both sides of the heat exchanger (with precision lines of $\S 10 \%)$

\subsection{Modeling the expansion machines}

The expansion machine is probably the most critical and the most widely investigated component of ORC systems, either through experimental studies or simulation works. Indeed, the device is responsible for the conversion of the working fluid energy content into mechanical energy at the shaft and several investigations have demonstrated the influence of the expander efficiency over the global performance of ORC system (e.g. [15], [16]). Among the existing expander technologies, none has been identified to be the optimal one ([16]), partly because the selection of the expander depends on various parameters such as compactness, cost, availability, etc. In literature, the device is often a compressor adapted to operate in expander mode. Otherwise experimental studies are conducted on prototypes. Most studies focus on volumetric expanders because of their ability to handle large pressure ratios while keeping the rotational speed limited. In his thesis, Declaye [17] proposed an overview of the experimental studies achieved on volumetric expanders between 1985 and 2012. Turbo-expanders are also more and more investigated because they can handle larger mass flow rates and lead to a more important specific power. To select the most suitable expander for the WHR application, 5 of the main technologies of volumetric expanders are investigated and compared here: the scroll, screw, piston, vane and roots expanders. Few authors have compared the performance of expander experimentally (e.g. [18], [19]). Here, the 5 volumetric machines have been investigated experimentally, whether directly in the Thermodynamic laboratory of the University of Liege (scroll, screw, piston and roots expanders) or in foreign laboratory through collaborative works (vane expander).

Measurements are used to calibrate and validate simulation models of the devices comparing the outputs of the model with the measurements. This is performed for the five volumetric machines together in for the shaft power, rotational speed and outlet temperature. The rotational speed, normally an input of the model, has been set as output instead of the mass flow rate, which is now an input, to reduce the computational time during the optimization process. The mean relative error on the speed and power prediction is around $6 \%$. The maximal error on both outputs reaches $15 \%$ for the vane expander model. The outlet temperature is generally predicted within a $10 \mathrm{~K}$ absolute error. More information on the radial inflow turbine and its modeling can be found in [22]. 


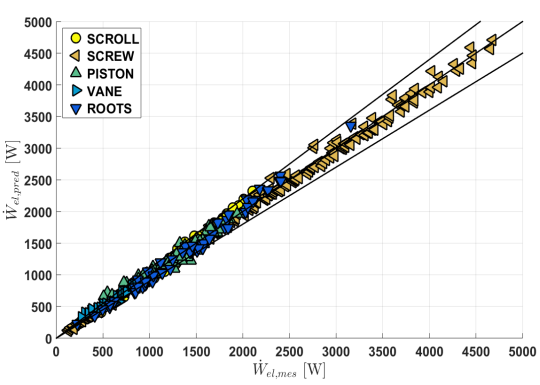

Fig.4 Comparison between measured and predicted shaft power production of the 5 expander technologies (with precision lines of $10 \%$ )

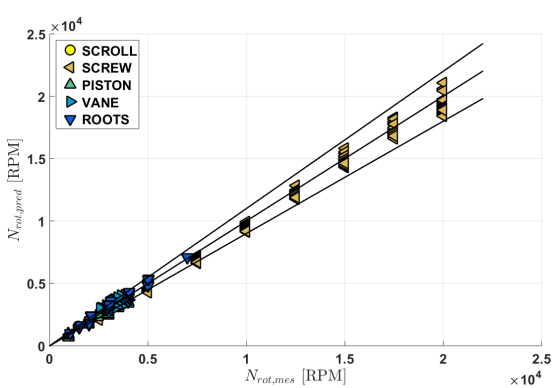

Fig.5 Comparison between measured and predicted rotational speed of the 5 expander technologies (with precision lines of $10 \%$ )

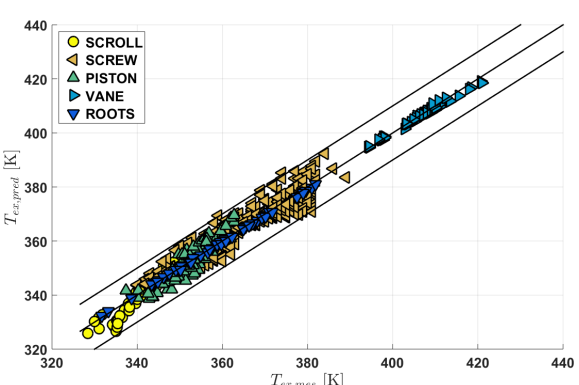

Fig.6 Comparison between measured and predicted outlet temperature of the 5 expander technologies (with precision lines of $10 \mathrm{~K}$ )

\subsection{Modeling the pump}

While it is not often considered in literature, the pump is a key component of the ORC system. In his thesis, Declaye [17] reviewed several publications dedicated to pump systems. He showed that only a limited number of authors have experimentally investigated pump system performance into details. Otherwise authors generally focused on the other ORC components and a constant efficiency is often considered in numerical studies. From this state of the art, a maximal isentropic efficiency of $81 \%$, based on the pump mechanical power consumption, has been reached by Lin [23] with a piston pump operating with water as working fluid. In addition, Declaye also experimentally investigated 5 different pump technologies: a single membrane, a multi-membrane, a gear, a plunger and an open piston pump. More information about the test-rigs and sensor properties can be found in the document. All machines together, the maximal achieved isentropic efficiency was around 50\%. This includes however, the loss of the driving and speed regulation systems. In laboratory, the pump is typically coupled to an electrical motor whose rotational speed can be regulated through a variable frequency drive. Those devices are leading to additional irreversibilities particularly in part load operation.

Because the considered pumps are volumetric devices, a similar modeling approach as the one proposed for the expansion machines is used. Considering the leakage, mechanical and electric conversion losses while putting aside the limited pressure drop losses at the inlet and outlet ports of the system and neglecting the compressibility effects, an explicit model can be achieved.

\subsection{Modeling the complete ORC systems}

The global model of the system is obtained by interconnecting the component models together. The inputs of the model are the inlet conditions of mass flow rate and temperature of the heating and cooling fluids. The evaporating pressure and the superheating degree are also selected as inputs. The outputs are the thermodynamic state at each point of the cycle as well as the heat flow rates on both sides of the exchangers and the mechanical power of the rotating machines. Solving the model is an iterative process that involves 2 to 5 iteration variables according to the architecture complexity. The model procedure is given in Figure 7 for the simplest of the investigated configurations, which involves a single heat source. In that case, it is proposed to iterate on the mass flow rate and the condensing pressure until converging on 2 criteria related to the heat exchangers. Those criteria vary according to the model configuration. In design mode, the pinch points of the heat exchangers are defined as optimization variables, as it will be seen. They are thus used to converge on both variables. In simulation mode, the heat transfer areas of the evaporator and condenser are known and are then used to solve the equation system. The system model also requires the parameters of each component model. In practice, pump and expander speeds are the 2 main degrees of freedom for the operator of an ORC system. The regulation of the pump speed 
enables to control the superheating degree at the expander inlet while the regulation of the expander speed (in the case of volumetric machines) enables to control the evaporating pressure for given working fluid mass flow rate and heat input. However, the model is numerically more robust when using directly the evaporating pressure and working mass flow rate as inputs. The main assumption for the evaluation of the performance in design and off-design is the sub-cooling degree at the outlet of the condenser, which is imposed to $5 \mathrm{~K}$. This assumption is relevant during the design phase. In simulation, however, it should be relaxed and the sub-cooling degree should become an output of the model and calculated, for instance applying the mass conservation of the working fluid used in the system. Nonetheless, this calculation would largely increase the computational time during the optimization phase without providing a significant increase in the accuracy of the prediction of the performance of the system at this stage.

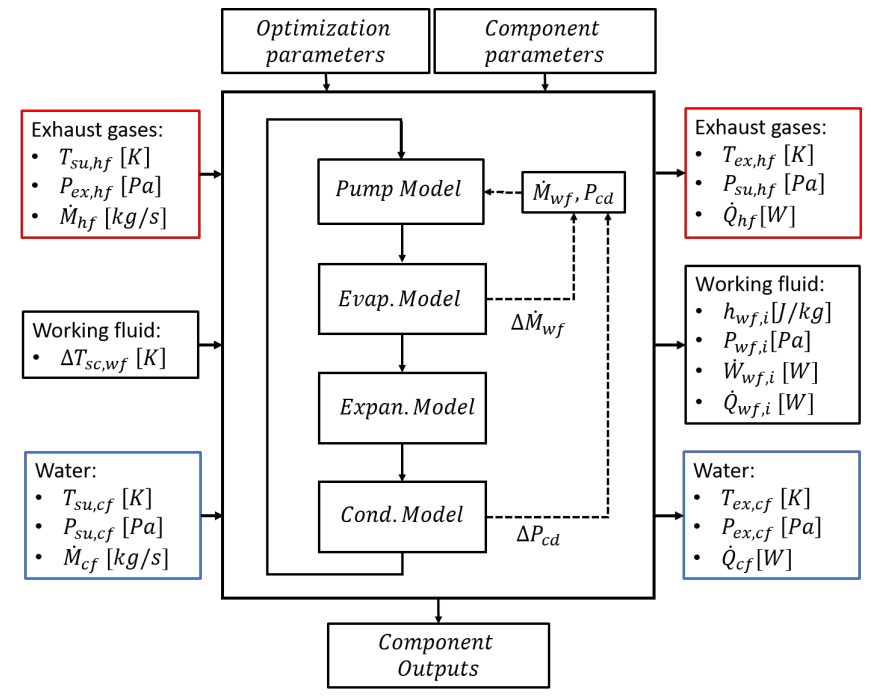

Fig. 7 Schematic of the ORC system model using a single heat source [22]

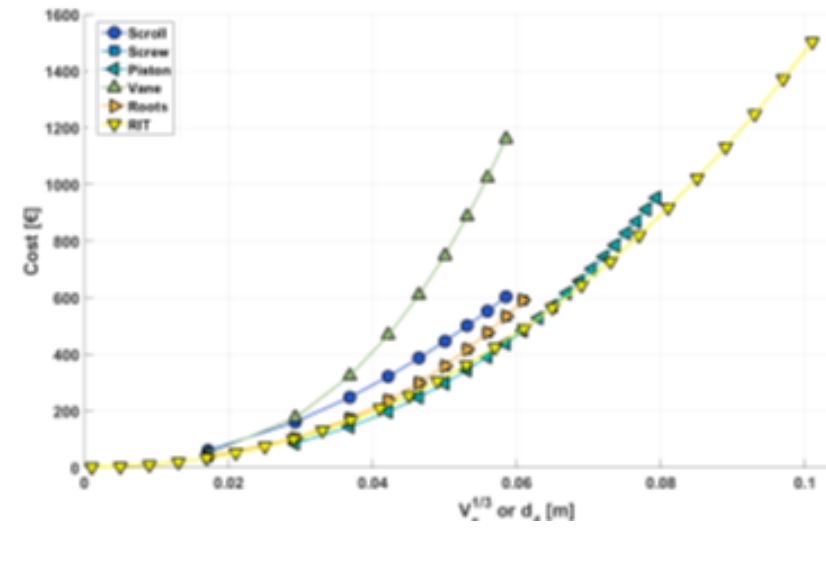

Fig.8 Evolution of the cost of the 6 investigated expansion machines as a function of

the characteristic length

\subsubsection{Economic model}

The objective of the design optimization process is the minimization of the specific investment cost (SIC), defined as the ratio between the Total Investment Cost (TIC) and the net power output of the system. The TIC is the sum of the Direct Costs (DC) and Indirect Costs (IC). In the DC can be found the cost of the system components, of the fluid, of the piping and of the instrumentation and control of the system. The IC are mainly composed of the engineering and contingency costs. Except for the cost of the system, assumptions are achieved for the DC and the IC based on discussion with manufacturers. The costs of the expansion machine technologies are estimated using Solidworks software [24]. 3D sketches have been performed or directly used when available, to establish the list of the main parts of the machines and to evaluate their costs as a function of the displacement of the expander. The process has been achieved assuming the type of material, the fabrication process and a serial production of 20.000 machines per year. Stainless steel material has been selected for parts directly in contact with the working fluid while carbon steel has been chosen for the other so to decrease the price. Molding process has generally been preferred to machining in order to reduce the fabrication costs. Curves are shown in Figure 8 for the cost each of the 6 expander technologies as a function of the characteristic length defined as the cubic root of the displacement for the volumetric machines and the rotor diameter for the radial-inflow turbine (RIT).

\subsubsection{Optimization variables and constraints}

The constraints mainly concern the temperature of the gases at the outlet of the heat exchangers. This temperature must be kept above a limit, considered here at $100^{\circ} \mathrm{C}$, to avoid the condensation of 
acids. The return temperature of the EGR gases has also to be maintained below a certain level to limit the impact of the waste heat recovery system on the NOx reduction strategy. In this work, $120^{\circ} \mathrm{C}$ is selected as the upper limit. The maximal pressure of the system is limited to 32 bar while a minimal pressure of 1 bar is imposed. The vapor mass fraction of the working fluid at the end of the expansion is also characterized by a lower limit. A minimal vapor quality of 0.85 is selected. The optimization of the pinch-point of the heat exchangers affects the size of the corresponding heat transfer surface. Typically, the lower the pinch-point, the larger the heat transfer area. This also implies an additional weight that should be limited for a mobile application. Because the geometry of the heat exchanger is considered in the model, it is possible to evaluate the weight of the devices based on the heat transfer area and the geometric characteristics. In this work, the weight of the heat exchangers is limited to $60 \mathrm{~kg}$. Finally, even if often oversized, the radiator at the front end of the truck, or more generally, the heat rejection capacity of the truck is limited. Above a defined temperature level of the engine coolant (around $90^{\circ} \mathrm{C}$ ), the fan is activated to increase the mass flow rate of the cooling air. The fan is an important power consumer whose activation should be limited as much as possible to avoid consuming a part of the output power of the waste heat recovery system. For this reason, the heat rejection at the condenser of the ORC system should be limited. A limit of $50 \mathrm{~kW}$ is considered in this work. It can be noted that the typologies involving the recirculated gases as heat source present an advantage regarding this constraint since the gases are already cooled down using water in the basic version of the truck (without WHR system). When considering the detailed models in the design phase, additional optimization variables and constraints can be considered. The superheating degree is now optimized. The impact of the superheating on the expander performance is often limited, particularly for volumetric machines. The turbine efficiency increases with the TIT but this effect remains marginal compared to effect of the pressure ratio and rotational speed. Nonetheless, for given operating conditions, the superheating is a direct image of the working fluid mass flow rate and, in the design phase, therefore influences the size of the heat exchangers and the other ORC components. For volumetric expanders, the built-in volume ratio and the rotational speed can be optimized. For turbines, the flow coefficient is considered instead. The inlet temperature, the built-in volume ratio (resp. the flow coefficient), the rotational speed and the pressure ratio are generally limited for each volumetric (resp. turbine) machine technology. Constraints are also considered for the blade angles and dimension of the turbine. Finally, during the off-design optimization, the geometry of the components is fixed and the pinch-points of the heat exchangers become outputs of the model. In practice, the rotational speeds of the expander and pump should be regulated to optimize the evaporating pressure and working fluid mass flow rate (or superheating degree) respectively. However, it is proposed to optimize directly the latter values and set the rotational speeds of the two components as outputs to improve the robustness of the numerical model.

\section{Selection of the design conditions}

The first step of the design process is the selection of the design conditions. To this end, the frequency distribution of the pairs engine torque-engine speed over the driving cycle is mapped. In this study, 5 torque and 6 speed levels are considered, which leads to 17 operating points. For each of these points, the systems are designed based on a model including a simplified version of the expansion machine (only considering over- and under-expansion losses). The superheating degree and the built-in volume ratio of the expander are fixed and the evaporating pressure and the pinchpoint of the heat exchangers of the various typologies are optimized for the investigated working fluids so to minimize the specific investment cost of the system. The mass of the heat exchangers is constrained to a limit of $60 \mathrm{~kg}$ while the pressure is limited to a maximum of $32 \mathrm{bar}$ based on the information coming from a truck manufacturer. Then the power produced by each topology is maximized in off-design for the other 16 operating points, still optimizing the evaporating pressure. Finally, for each of the 17 systems designed, an average is performed on the power produced and 
weighted over the 17 points using the frequency distribution so to identify the most promising design conditions for each topology and each fluid. Results are shown in Figure 9 where the specific investment cost is drawn against the heat flow rate available in the gases for 3 typologies using ethanol as working fluid and 2 values of built in volume ratios. As it can be seen, the curves pass through a minimum, which should be selected as design point. However, values of SIC on the right side of this minimum remain close to minimal value for each curve. So the most important trend is to avoid the 6 operating points corresponding to a lower heat level available in the gases.

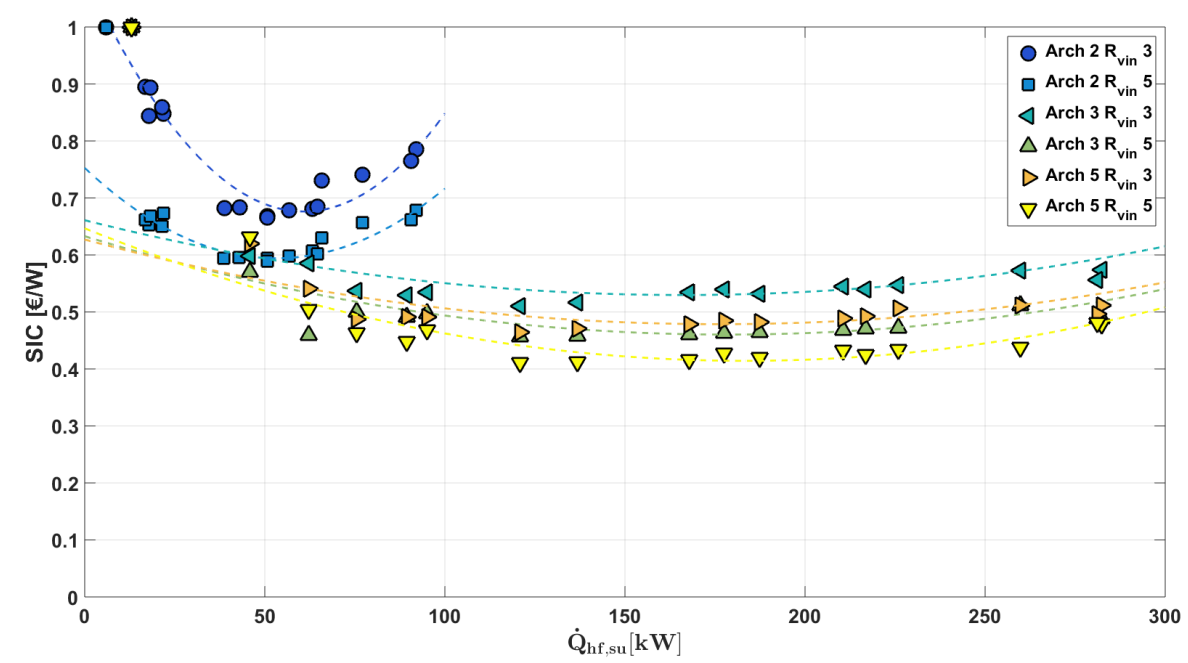

Fig. 9 Evolution of the specific investment cost, obtained with the simplified model, as function of the available supply heat flow rate for 3 typologies and ethanol as working fluid

\section{Design phase: thermo-economic optimization}

The interior-point algorithm through the Matlab optimization toolbox is used to perform the minimization of the SIC of each system. The typologies are first compared in terms of net power output and specific investment cost. The influence of the working fluid and of the expansion machine is also discussed. Based on the results, the distribution of the costs and the fuel economy expected on the design point are presented for the most promising architectures.

Results in terms of SIC are shown in Figure 10. It can be observed that typologies 2 to 5, including the EGR as heat source are the most promising whatever the working fluid. Typology EGR Last is generally unfeasible because of the upper limit on the outlet temperature of the EGR gases $\left(120^{\circ} \mathrm{C}\right)$. The use of the recirculated gases as single heat source presents the advantage not to increase the heat rejection of the truck. In general, ethanol seems to be the most appropriate working fluid. Also, because of the low temperature of the heat source, water should be avoided using typology 1. Moreover, water is not well suited with the vane and roots expanders. This is explained by the constraint on the maximal inlet temperature within this technology. Fluid R245fa generally leads to higher SIC and should be avoided, except when the exhaust gases are used as single heat source. This is due to the relatively low temperature level of those gases. The most promising expansion devices seem to be the scroll and screw expander while the piston and turbine expanders lead to slightly higher SIC. The vane and roots expanders generally lead to higher SIC because of their corresponding limitations. Finally, the most appropriate solution, based on the assumptions made here is the use of the screw expander integrated in the parallel typology and using ethanol as working fluid. In this configuration, the SIC is below 0.23 while the net output power of the system almost reaches $10 \mathrm{~kW}$. However, the results obtained with the scroll expander in the same conditions remain very similar. Cyclopentane, water and acetone also show good performance when used in architecture 2, 3 and 5 with the scroll and screw expander. At this stage no conclusion can thus really be drawn. 

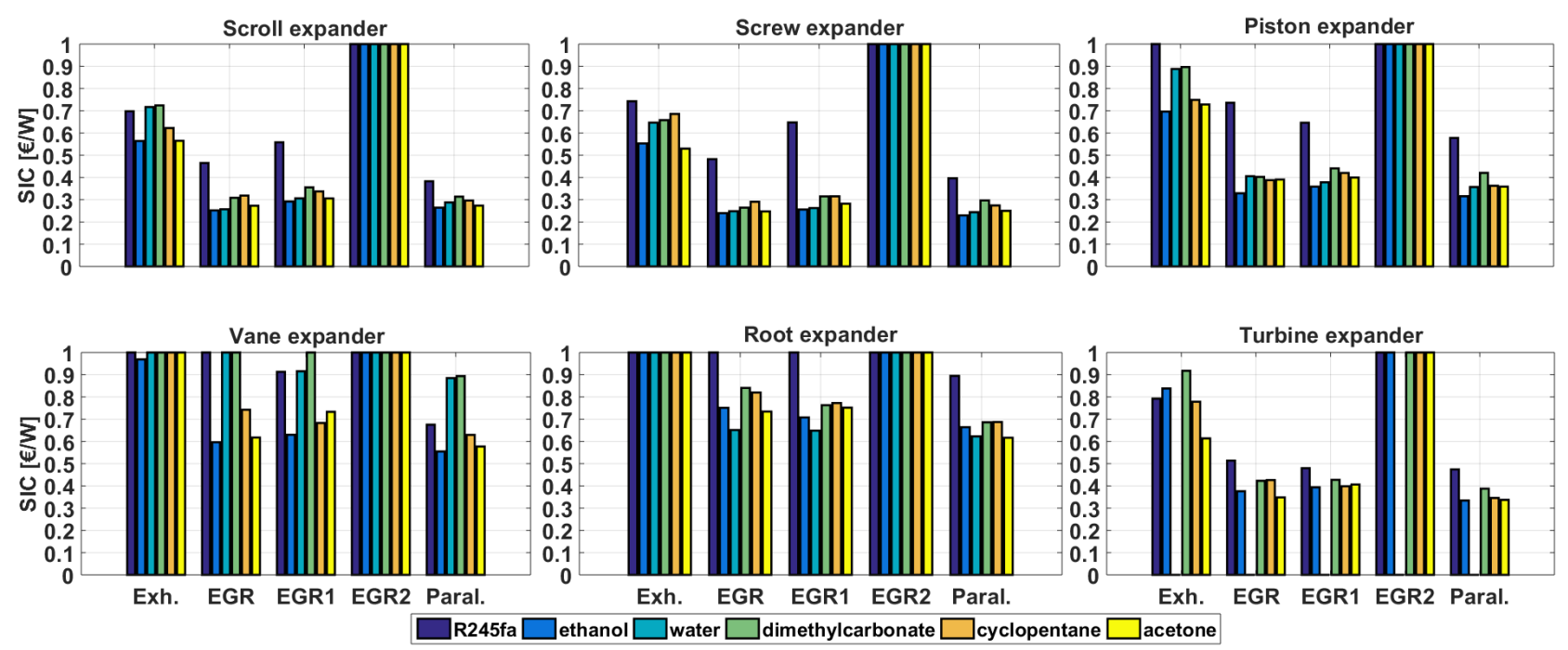

Fig. 10 Specific Investment Cost of the ORC systems achieved on the design point with the different architectures, working fluids and expansion machines

\section{Off-design optimization}

Finally, the performance of the 3 most promising architectures (2, 3 and 5) are maximized optimizing the evaporating pressure and the superheating degree for each of the 16 off-design operating points of the frequency distribution map. It is worth noting that the optimization of the evaporating pressure (or expander rotational speed) implies the use of an electrical generator and a speed regulation mechanism. Whether turbines or volumetric machines are considered, the control of the expander rotational speed enables to optimize the power production and adapt it to the vehicle electrical consumption. However, the latter can hardly be predicted and is today too low (around $1.5 \mathrm{~kW}$ ) to absorb the production of an ORC system, which could be up to $10 \mathrm{~kW}$ depending on the engine operating point. An alternative enabling to estimate the fuel economy is to couple the ORC generator to an electric motor through batteries. A mechanical coupling of the engine and expander shafts is probably the simplest solution, but it also implies the loss of a degree of freedom for the optimization and control the WHRS: the regulation of the evaporating pressure through the rotational speed of the (volumetric) expander is no more possible. A weighted average based on the frequency distribution is performed for the net power outputs of the systems. This is achieved here for the 2 most promising expansion machines, the scroll and the screw expander. Results are reported in Figure 11 in terms of weighted average net power output. A new estimation of the SIC is provided based on the latter weighted average power. In general, using the recirculated gases as the single heat source is less suited compared to the 2 other typologies. The average power is reduced, leading to a higher SIC. The parallel typology gives slightly better results compared to the serial topology. It enables to extract more heat from the heat source thanks to an additional degree of freedom ( 2 working fluid mass flow rates). Results are similar when comparing the performance of the systems using the scroll and the screw expanders. The lowest SIC values are achieved with ethanol as working fluid. However, the average output power obtained with cyclopentane and acetone is of the same order of magnitude and even higher sometimes. 

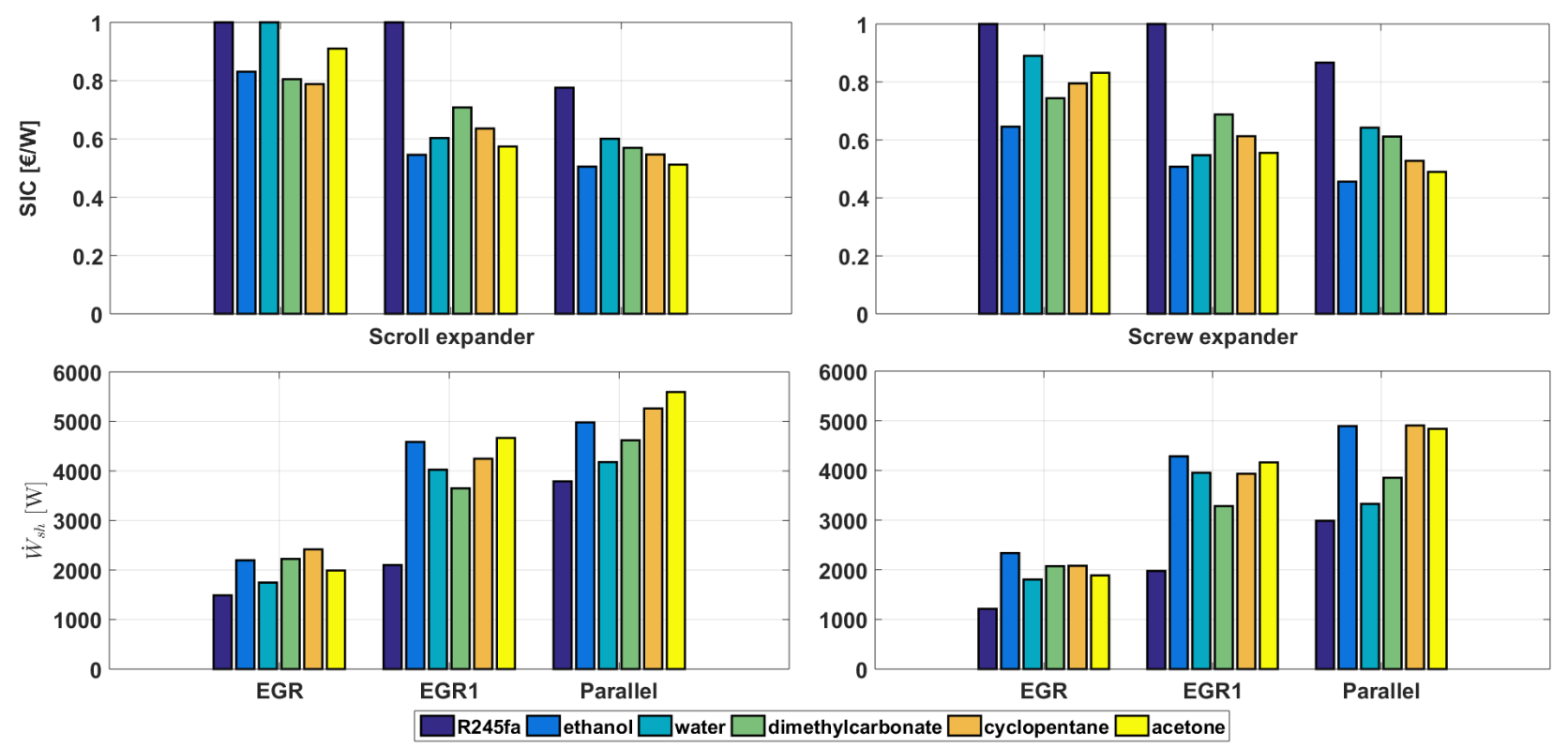

Fig. 11 Weighted average of the net power outputs of the ORC system and resulting specific investment costs achieved over all the investigated operating conditions for the 3 most promising architectures, the 6 working fluids and the scroll and screw expanders

Based on the simulation results, economic indicators (Figures 12 and 13) can already be introduced and evaluated. The first introduced indicator is the payback period, which is commonly defined for project investments. This period $(\mathrm{P})$ is the length of time needed to recover the cost of an investment $(\mathrm{C} 0)$, i.e. the recover the capital investment thanks to the fuel savings in the present study. It is assumed, the investment to be made by the future truck owner, or the price of the WHR system, is 1.5 the manufacturer TIC. Considering HDT travel $150000 \mathrm{~km}$ per year, are characterized by a life length of 10 years (or $1500000 \mathrm{~km}$ ) and consumes in average $351 / 100 \mathrm{~km}$ with a diesel price of $1.1 \mathrm{l} / 1$, the time required to recover the investment of the WHR ORC systems is:

$$
\begin{aligned}
C_{0} & =1.5 . T I C \\
P & =\frac{C_{0}}{A F S}
\end{aligned}
$$

where the annual fuel savings (AFS) are the product of the amount of fuel saved per year thanks to the WHR system and the fuel price in $€ / 1$. The payback period unlike other methods, does not consider the time value of money. "Because of the time value of money (TVM), money in the present is worth more than the same amount in the future. This is both because of earnings that could potentially be made using the money during the intervening time and because of inflation. In other words, a dollar earned in the future won't be worth as much as one earned in the present" [25]. The Net Present Value (NPV), through the discount rate, is a way to account for these characteristics of money. The NPV, defined as follow, is the net values of the cash inflow and is used to investigate the profitability of a project.

$$
N P V=\sum_{t} \frac{C_{t}}{(1+r)^{t}}-C_{0}
$$

where $C_{t}$ is the net cash inflow of the period $\mathrm{t}, \mathrm{r}$ is the discount rate and $\mathrm{N}$ the number of investigated periods. When positive, the NPV indicates the earnings of a project are above the expenses and the project is profitable. The challenging part in using the NPV is the identification of the discount rate and future cash inflows and outflows of the project. A discount rate of $10 \%$ is considered while the only cash inflows and outflows are the annual fuel savings tanks to the WHR system and the annual maintenance costs (100€/year [26]). Starting from a fuel price of $1.1 € / 1$ a yearly increase of $5 \%$ of this price is also assumed. A third economic indicator is the Internal Rate of Return (IRR) of investment. The formula used is the same as the NPV. However, the method consists in identifying the discount rate that makes the NPV of all cash flows equal to 0 at the end 
of the project. In general, the higher the IRR, the higher the chance of a project to be profitable. The IRR is also representative of the rate of growth of a project. Indeed, even if the IRR differs from the actual rate of return, the project with the higher IRR provides more chance to be substantially profitable.
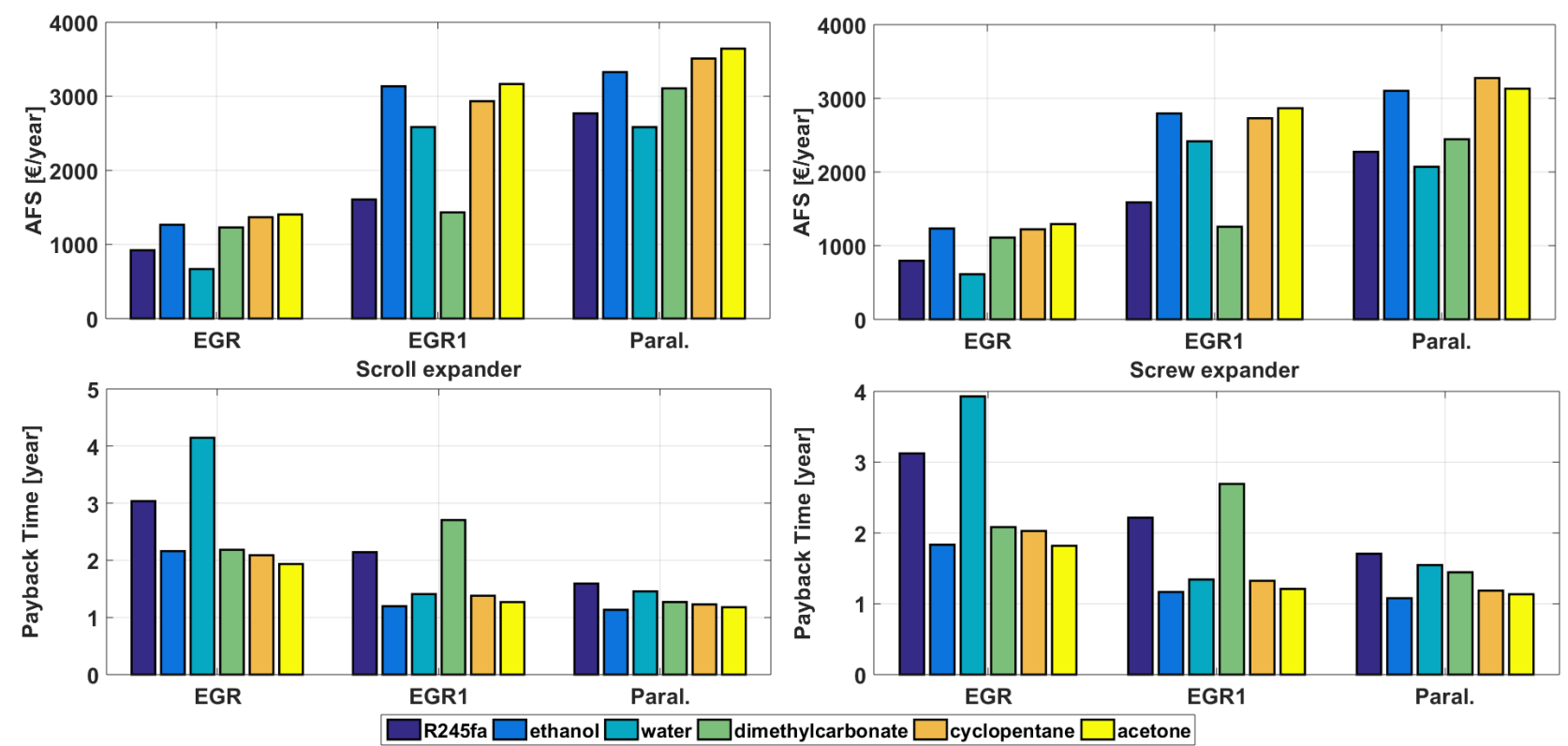

Fig. 12 Weighted average of annual fuel savings and payback time achieved over all the investigated operating conditions for the 3 most promising architectures, the 6 working fluids and the scroll and screw expanders
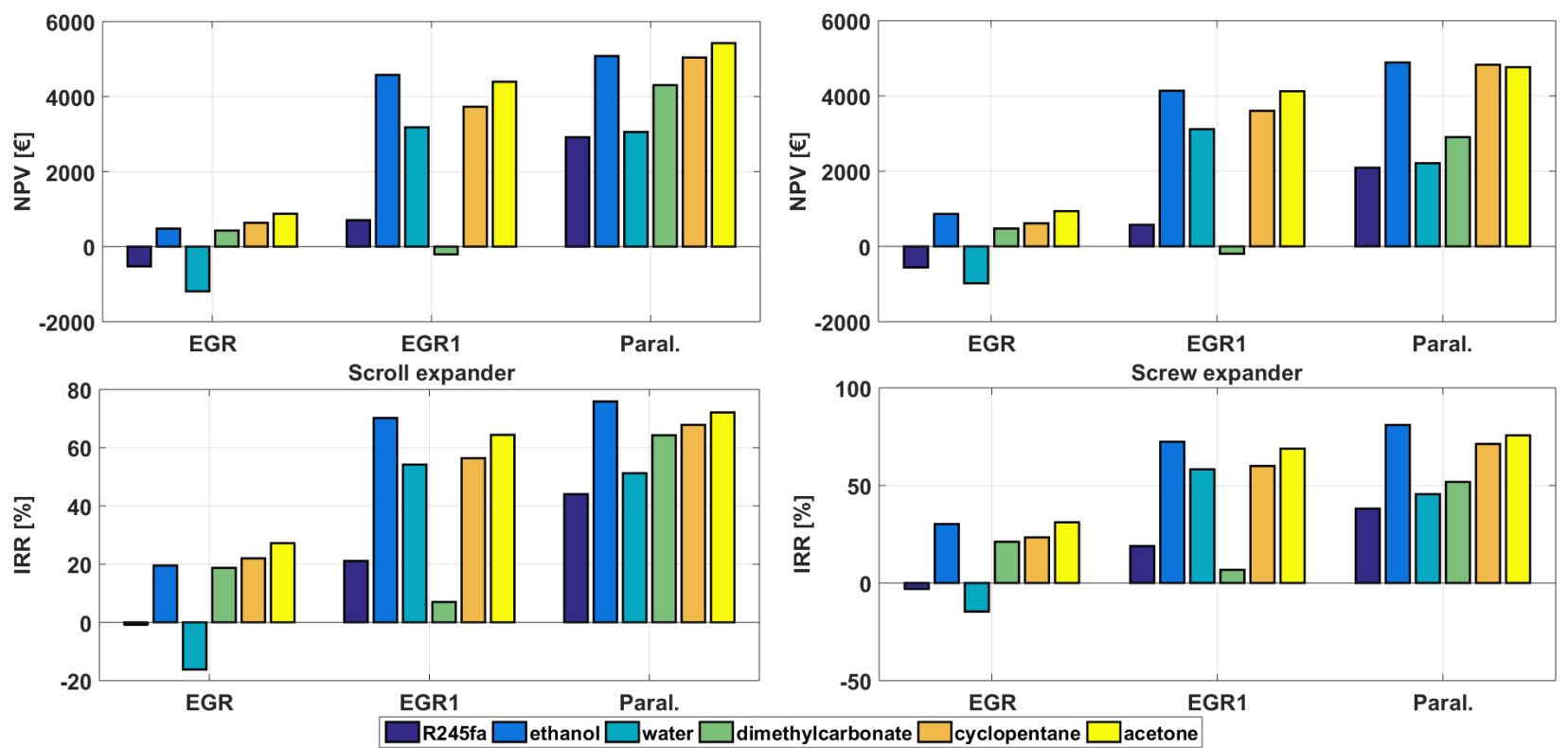

Fig. 13 NPV and IRR achieved over all the investigated operating conditions for the 3 most promising architectures, the 6 working fluids and the scroll and screw expanders

\section{Conclusion}

This work contributes to the development of tools and methodologies for the selection of the architecture, the expander technology, and the working fluid for a waste heat recovery organic (or non-organic) Rankine cycle system devoted to be coupled to a truck engine. First, the component models are built and validated against experimental data before trying to predict their performance within the design phase of the on-board system. A Rankine test-bench, using water as working 
fluid, and devoted to recover the heat from the exhaust gases of a gasoline engine, enabled to validate the plate heat exchanger model to be placed on the high-pressure side of the ORC system. Regarding the plate heat condensers, because the pinch-point is generally low, it is proposed to directly use correlations available in literature to evaluate the heat transfer coefficients on both sides of the heat exchanger. Validated models of scroll, screw, piston, vane, roots expanders, of a radial inflow turbine and of a piston and membrane pump are proposed. These models are used as reference for the design process whose strategy consists in scaling the components for the new application following specific rules. From the 5 architectures proposed and the 6 expander technologies result 30 different typologies. Considering 6 working fluids, it leads at the end the optimization of 180 ORC system models. A 3-step optimization is proposed. The method starts with the selection of the design conditions. Then, for the obtained design conditions, a thermo-economic optimization is performed to design the systems. Finally, the performance of the resulting systems is optimized and evaluated for various off-design conditions, optimizing the evaporating pressure and the superheating degree. It is therefore assumed the expander speed can be controlled. On the other hand, a mechanical coupling of the engine and expander shafts could be investigated but it would also imply the expander speed is imposed by the engine through a gear ratio. A weighted average of the power produced by the systems is then done based on the frequency distribution of the considered operating conditions in the driving cycle. Based on the results, it is shown that ethanol is the most appropriate working fluid while the EGR First and parallel typologies are the most promising. The use of the screw expander leads to the best average performance. However, results are similar between the scroll, the screw expanders. At the end, 4 architectures are then retained. Quasi-static simulations could be performed along driving cycles of the truck to evaluate the energy recovered by the systems and thus the fuel consumption reduction.

\section{Nomenclature}

\section{Letter symbols}

A heat transfer area, $\mathrm{m}^{2}$

$A U$ Global heat transfer coefficient, $\left(\mathrm{W} / \mathrm{m}^{2}\right)$

c specific heat, $\mathrm{J} /(\mathrm{kg} \mathrm{K})$

$e \quad$ wall thickness, $\mathrm{m}$

$h$ convective heat transfer coefficient, $\mathrm{W} /\left(\mathrm{m}^{2} \mathrm{~K}\right)$

$k$ thermal conductivity, $W /(m K)$

$\dot{m}$ mass flow rate, $\mathrm{kg} / \mathrm{s}$

$\mathrm{P}$ pressure, $\mathrm{Pa}$

$\dot{Q}$ heat flow rate, $\mathrm{W}$

$T \quad$ temperature, ${ }^{\circ} \mathrm{C}$

$\mathrm{U}$ heat transfer coefficient, $\mathrm{W} /\left(\mathrm{m}^{2} \mathrm{~K}\right)$

$\mathrm{W}$ mechanical power, $\mathrm{W}$

\begin{tabular}{|c|c|c|c|}
\hline \multicolumn{2}{|c|}{ Greek symbols } & \multirow{2}{*}{$\begin{array}{l}\text { hf } \\
\text { liq }\end{array}$} & \multirow{2}{*}{$\begin{array}{l}\text { hot fluid } \\
\text { liquid }\end{array}$} \\
\hline$\Delta$ & difference & & \\
\hline & efficiency & LM & Logarithmic \\
\hline$p$ & filling factor & mes & measured \\
\hline \multicolumn{2}{|c|}{$\begin{array}{l}\text { Subscripts and } \\
\text { superscripts }\end{array}$} & $\mathrm{sf}$ & $\begin{array}{l}\text { secondary } \\
\text { fluid }\end{array}$ \\
\hline $\mathrm{amb}$ & ambient & $\mathrm{sp}$ & single phase \\
\hline calc & calculated & tot & total \\
\hline $\begin{array}{l}\mathrm{cf} \\
\mathrm{conv}\end{array}$ & $\begin{array}{l}\text { cold fluid } \\
\text { convection }\end{array}$ & tp & two-phase \\
\hline eg & exhaust gases & vap & vapor \\
\hline$g r$ & $\begin{array}{l}\text { exhaust } \quad g \\
\text { rculation }\end{array}$ & $\begin{array}{l}\text { wall } \\
\text { wf }\end{array}$ & $\begin{array}{l}\text { wall } \\
\text { working flui }\end{array}$ \\
\hline
\end{tabular}

\section{References}

[1] ESPINOSA N. Contribution to the study of waste heat recovery systems on commercial truck diesel engines. Institut National Polytechnique de Lorraine, Ecole doctorale EMMA, 2011.

[2] GRELET V. Rankine cycle based waste heat recovery system applied to heavy duty vehicles: topological optimization and model based control. PhD thesis, University of Lyon, Lyon, France, 2016.

[3] GUNNAR L. Waste heat recovery from combustion engines based on the rankine cycle. Chalmers university of Technology 2016, Gothenburg, Sweden. 
[4] ARUNACHALAM P, SHEN M, TUNER M, TUNESTAL P, THERN M. Waste heat recovery from multiple heat sources in a hd truck diesel engine using a rankine cycle - a theoretical evaluation. SAE Technical Paper 2012-01-1602, 2012, doi:10.4271/2012-01-1602.

[5] YAMAGUCHI T, AOYAGI Y, UCHIDA N, FUKUNAGA A, KOBAYASHI M, ADACHI T, HASHIMOTO M. Fundamental study of waste heat recovery in the high boosted 6-cylinder heavy duty diesel engine. SAE Int. J.Mater.Manf. 2015; 8(2): 209-226.

[6] ALLOUACHE A, LEGGETT S, HALL M, TU M, BAKER C, FATEH H. Simulation of organic rankine cycle power generation with exhaust heat recovery from a 15 liter diesel engine. SAE Int. J.Mater.Manf. 8(2):227238, 2015, doi:10.4271/2015-01-0339.

[7] AMICABILE S, LEEB JI, KUM D. A comprehensive design methodology of organic rankine cycles for the waste heat recovery of automotive heavy-duty diesel engines. Applied

Thermal Engineering 2015; 87:574-585.

[8] XIE H, YANG C. Dynamic behavior of rankine cycle system for waste heat recovery of heavy duty diesel engines under driving cycle. Applied Energy 2013; 112: 130-141.

[9] CIPOLLONE R, DI BATTISTA D, PEROSINO A, BETTOJA F. Waste heat recovery by an organic rankine cycle for heavy duty vehicles. SAE Technical Paper 2016; SAE International.

[10] LECOMPTE S, HUISSEUNE H, VAN DEN BROEK M, SCHAMPHELEIRE SD, DE PAEPE M. Partload based thermo-economic optimization of the organic rankine cycle (orc) applied to a combined heat and power (chp) system. Applied Energy 2013; 111: 871-881.

[11] MATHWORKS. Matlab: The language of technical computing. 2017; https://nl.mathworks.com/.

[12] NELLIS G, KLEIN S. Chapter 8. Heat Transfer 2009, Cambridge University Press.

[13] AYUB ZH. Plate heat exchanger literature survey and new heat transfer and pressure drop correlations for refrigerant evaporators. Heat Transfer Engineering 2003; 24(5):3-16.

[14] DUMONT O. Experimental investigation of the valorization of the waste heat of a gasoline engine based on a rankine cycle.

[15] ZIVIANI D, BEYENE A, VENTURINI M. Design, analysis and optimization of a microchp system based on organic rankine cycle for ultralow grade thermal energy recovery.

Journal of Energy Resources Technology;136:1.

[16] QIU G, LIU H, AND RIFFAT S. Expanders for micro-chp systems with organic rankine cycle. Applied Thermal Engineering 2011;31:3301-3307.

[17] DECLAYE S. Improving the performance of micro-ORC systems. PhD thesis, University of Liege, Liege, Belgium, 2015.

[18] MIKIELEWICSZ D, MIKIELEWICSZ J, WAJS J. Experiences from operation of different expansion devices for application in domestic micro chp. Archives of Thermodynamics 31, 4.

[19] DUMONT O. Experimental investigation of four volumetric expanders.

[20] DICKES R, DUMONT O, DACCORD R, QUOILIN S, LEMORT V. Modelling of organic rankine cycle power systems in off-design conditions: An experimentally-validated comparative study. Energy 2017, In Press, Accepted Manuscript, doi:10.1016/j.energy.2017.01.130.

[21] LEMORT V, QUOILIN S, CUEVAS C, LEBRUN J. Testing and modeling a scroll expander integrated into an organic rankine cycle. Applied Thermal Engineering 2009; 29:3094-3102.

[22] GUILLAUME L., On the design of waste heat recovery organic Rankine cycle systems for engines of longhaul trucks, PhD thesis, University of Liege, Liege, Belgium, 2015.

[23] LIN C. Feasibility of using power steering pumps in small-scale solar thermal electric power systems. Bachelor Thesis 2008, Massachusetts Institute of Technology, Dept. of Mechanical Engineering.

[24] SOLIDWORKS. 3d cad solutions. 2017; http://www.solidworks.fr/.

[25] WIKIPEDIA. Net present value - npv. URL http://www.investopedia.com/terms/n/npv.asp; 2017.

[26] EXOES. L'avenir du moteur thermique. http://www.exoes.com. 